\title{
Pelatihan Peningkatan Keterampilan Servis Backhand bulutangkis Melalui Media Audio Visual di SMPN 1 Mataram
}

\author{
Soemardiawan, Intan Primayanti, Aminullah, Indri Susilawati \\ Fakultas Pendidikan Olahraga Kesehatan, FPOK IKIP (Soemardiawan) \\ Email: umanksoemardiawan84@gmail.com
}

\begin{abstract}
Abstrak; Pelatihan pengembangan media pembelajaran multimedia dengan pemanfaatan Media audio meningkatkan keterampilan servis backhand dan forehand bulutangkis visual Peralatan audio visual bertujuan untuk memberikan ketrampilan dalam pembuatan media pembelajaran multimedia audio visual yang menarik dengan cara yang relatif mudah. Dengan dikuasainya media pembelajaran multimedia oleh para guru penjas diharapkan akan pemicu minat siswa untuk lebih bersemangat dalam mengikuti pelajaran, dan pada akhirnya akan meningkatkan kualitas pembelajaran secara keseluruhan. Metode yang diterapkan dalam kegiatan ini adalah Metode Presentasi mengenai pengenalan software, media audio visual, kemanfaataannya, dan penerapannya dalam pembuatan media pembelajaran interaktif, Metode Demonstrasi mengenai pengoperasionalisasian program dan Metode Praktik yaitu pembuatan media pembelajaran secara langsung oleh peserta sesuai dengan mata pelajaran masing-masing dengan pemanfaatan programMedia audio visual. Metode evaluasi dengan mengamati perbedaan kemampuan guru sebelum dan setelah pelatihan. Dari hasil yang dicapai terlihat peningkatan kemampuan yang cukup signifikan dibanding dengan sebelum dilatih, sehingga dapat disimpulkan bahwa kegiatan ini berhasil meningkatkan kemampuan peserta. Evaluasi hasil dilihat dari penilaian tugas praktik yang menggambarkan keberhasilan materi yang telah disajikan.Selain itu juga dicermati kinerja dan partisipasi para peserta.Di akhir kegiatan Tim menjaring data kebermaknaan program pada para peserta.Diharapkan agar program pelatihan ini terus diadakan karena sangat dirasakan manfaatnya untuk meningkatkan kualitas pembelajaran media audia visual memungkinkan menggunakan gambar hidup, pemutaran kembali suara, dan penayangan visual yang berukuran besar.
\end{abstract}

\section{Kata Kunci : Pelatihan Media Pembelajaran, Audio Visual, Guru SMP}

\section{PENDAHULUAN}

Permainan bulutangkis adalah suatu permainan bola kecil yang dimainkan dengan saling berhadapan satu orang melawan satu orang yang biasa disebut pemain singel atau dua orang melawan dua orang yang disebut pemain double dalam permainan bulutangkis Permainan bulutangkis menggunakan alat raket dan shuttlecock. Untuk bermain bulutangkis, setiap pemain harus berusaha menguasai berbagai teknik dasar dalam permainan bulutangkis, diantaranya: teknik memegang raket, teknik menguasai posisi siap berdiri, teknik mengatur

Oleh karena itu, guru pendidikan jasmani harus mampu membuat pembelajaran yang efesien, efektif serta menyenangkan Servis Backhand adalah teknik memukul shuttlecock dengan posisi punggung tangan menghadap ke depan/ke arah datangnya shuttlecock. Servis ini pada umumnya arah jatuhnya shuttlecock sedekat mungkin dengan arah garis serangan lawan dan shuttlecock sedapat mungkin melayang relatif dekat dengan jaring net.

Dari uraian di tersebut, dapat disimpulkan bahwa proses pembelajaran menggunakan media audio visual merupakan salah satu alternatif dalam meningkatkan kualitas pembelajaran terutama untuk materi teknik dasar servis backhand permainan bulutangkis. Melalui proses dengan menggunakan media audio visual pembelajaran menjadi lebih hidup, jauh dari rasa bosan dan menarik. Melalui media audio visual, siswa dapat melihat dan mendengar langsung apa yang dijelaskan guru. Penggunaan media audio visual pada pembelajaran teknik dasar servis backhand permainan bulutangkis. 
Media memungkinkan siswa menyentuh objek kajian pelajaran. Hal ini membantu siswa mengongkritkan suatu yang abstrak dan membantu pendidik menghindari proses pembelajaran yang cepat membuat siswa jenuh.

Berdasarkan uraian dan penjelasan yang telah dipaparkan, penulis tertarik untuk memecahkan permasalahan tersebut dengan judul peningkatan keterampilan servis backhand bulutangkis melalui media alat bantu pada siswa SMPN 1 Mataram. Sukmadinata (2011:140) menjelaskan penelitian tindakan merupakan suatu pencarian sistematik yang dilaksanakan oleh para pelaksana program dalam kegiatanya sendiri (dalam pendidikan dilakukan oleh guru, dosen, kepala sekolah, konselor), dalam mengumpulkan data tentang pelaksanaan kegiatan, keberhasilan dan hambatan yang dihadapi, untuk kemudian menyusun rencana dan melakukan kegiatankegiatan penyempurnaan.

Kustandi mengatakan (2011:33), media pembelajaran dapat dikelompokkan ke dalam empat kelompok, yaitu (1) media hasil teknologi cetak, (2) media hasil teknologi audio visual, (3) media hasil teknologi yang berdasarkan komputer, (4) media hasil gabungan teknologi cetak dan komputer.

\section{METODE PELAKSANAAN PROGRAM PENGABDIAN MASYARAKAT}

Hasil akhir dari kegiatan penelitian tindakan adalah meningkatkan keterampilan siswa khususnya keterampilan servis backhand bulutangkis pada siswa ekstrakurikuler bulutangkis SMPN 1 Mataram dengan menggunakan pemanfaatan media alat bantu yaitu Media audio visual Peralatan audio visual memungkinkan menggunakan gambar hidup, pemutaran kembali suara, dan penayangan visual yang berukuran besar.

\section{Persiapaan Pelatihan}

Tahapan persiapan merupakan tahapa awal seblum melakaukan pelaksanaan program pengabdian kepada mayarakat. Dalam tahapan ini ada beberapa hal yang dilakukan yakni koordinasi internal, dilakukan oleh tim untk melaksanakan secara konseptual, operasional, serta job description masing masing anggota, penentuan dan rekrutment peserta pelatihan dalam perekrutan peserta dipersyaratkan memiliki keterampilan yang memadai dalam bidang Dalam bidang bulutangkis, Pembuatan media audio visual, pembuatan instrument program pengabdian masyarakat ini, lembar persensi, angket, lembar kerja, persiapan konsumsi publikasi, lokasi,dan dokumentasi.

\section{Pelaksanaan Pelatihan}

Pengabdian ini dilaksanakan di SMPN 1 Mataram jalan Pejanggik No 1 Mataram pada bulan April tahun 2019 sampai dengan selesai.

\section{1) Peyajian Materi}

Materi yang disajikan terkait dengan pengenalan dan penggunaan program Media audio visual adalah media yang penyampaian pesannya dapat diterima oleh indra pendengaran dan indra penglihatan yang secara eksklusif tidak selalu harus tergantung kepada pemahaman kata-kata dan symbol simbol sejenis .Penyajian ini diploting dalam 3 hari tatap muka. Penyaji materi adalah tim pengabdi sendiri disesuaikan dengan bidang keahlian masing-masing. Materi yang tersajikan sebanyak 5 (Lima) bahasan yang masing-masing disajikan oleh anggota Tim Pengabdi sesuai bidang yang bersangkutan. Berikut tabel daftar materi dan pematerinya yang telah terlaksana dalam program PPM ini

\begin{tabular}{|c|c|c|}
\hline \multirow{6}{*}{\begin{tabular}{|l|} 
Jenis \\
Kegiatan \\
\end{tabular}} & $\begin{array}{l}\text { Pokok } \\
\text { Bahasan }\end{array}$ & Pemateri \\
\hline & $\begin{array}{l}\text { Teknik Dasar } \\
\text { Perminan } \\
\text { Bulutangkis }\end{array}$ & Soemardiawan, M.Pd \\
\hline & $\begin{array}{l}\text { Pengenalan } \\
\text { Pembelajaran } \\
\text { Media audio } \\
\text { visual simbol } \\
\text { sejenis. }\end{array}$ & $\begin{array}{l}\text { Intan Primayanti, S.Pd., } \\
\text { M.Or }\end{array}$ \\
\hline & $\begin{array}{l}\text { Keterampilan } \\
\text { Servis } \\
\text { BackhandBulu } \\
\text { tangkis }\end{array}$ & Soemardiawan, M.Pd \\
\hline & $\begin{array}{l}\text { Media audio } \\
\text { visual Gerak } \\
\text { keterampilan } \\
\text { Bulutangis }\end{array}$ & $\begin{array}{l}\text { Intan Primayanti, S.Pd., } \\
\text { M.Or }\end{array}$ \\
\hline & $\begin{array}{l}\text { Membuat } \\
\text { Efek Suara }\end{array}$ & $\begin{array}{l}\text { Indri Susilawati, SST. } \\
\text { Ft., M.Fis }\end{array}$ \\
\hline $\begin{array}{l}\text { Praktek } \\
\text { Pembuat } \\
\text { an media } \\
\text { Media } \\
\text { audio } \\
\text { visual }\end{array}$ & & $\begin{array}{l}\text { Soemardiawan, } \\
\text { dan Intan Primayanti, } \\
\text { S.Pd., M.Or }\end{array}$ \\
\hline
\end{tabular}

Pelaksanaan program ini melibatkan mahasiswa untuk membantu proses pembimbingan dan praktik agar kegiatan dapat berjalan lancar. Kegiatan tanya jawab dilakukan bersamaan dengan penyajian materi. Para peserta dapat langsung berdiskusi dengan para pemateri secara langsung untuk memahamkan materi dan sharing pengalaman 
terkait dengan masalah yang tengah dibahas dalam materi bersangkutan.

\section{2) Penugasan Praktik}

Pada akhir materi peserta diberi tugas praktik sesuai materi yang telah disajikan untuk menggali penyerapan dan pemahaman materi serta melihat kreativitasnya dalam berkarya dalam hal media alat bantu yaitu Media audio visual Peralatan audio visual memungkinkan menggunakan gambar hidup, pemutaran kembali suara, dan penayangan visual yang berukuran besar. yang akan dilaksanakan oleh peyaji. Dalam pelatihan ini para guru ditugaskan untuk membuat satu media pembelajaran melalui Media audio visual terkait mata pelajaran bulutangkis yang diampu masing-masing guru penjas di Sekolah SMPN 1 Mataram. Tim pengabdian mendampingi, memandu dan mengarahkan serta memberikan solusi apabila timbul permasalahan selama penugasan praktik.

\section{3) Evaluasi dan Penyempurnaan Karya Media Pembelajaran oleh Tim}

Pada akhir pelatihan, media yang telah dibuat oleh para guru dikumpulkan dan dinilai oleh tim pengabdi kemudian disempurnakan oleh tim untuk kemudian dikembalikan kembali kepada peserta agar dapat digunakan untuk mengajar melalui media alat bantu yaitu Media audio visual Peralatan audio visual memungkinkan menggunakan gambar hidup, pemutaran kembali suara, dan penayangan visual yang berukuran besar. Tindakan ini dilakukan mengingat karya media yang dihasilkan para guru masih perlu penyempurnaan, dan tim tim pengabdi ingin agar media pembelajaran Media audio visual betul-betul dapat segera dimanfaatkan untuk mengajar.

\section{4) Refleksi dan Penutupan Program Pengabdian Masyarakat}

Di akhir kegiatan peserta dan Tim melakukan refleksi hasil pelatihan dan para peserta juga memberikan evaluasi akan pelatihan ini. Peserta mendapatkan koreksi dan evaluasi secara langsung terkait hasil karya mereka. Setelah semua kegiatan yang telah direncanakan terlaksana, ketua tim Pengabdian Masyarakat menutup program dan memberikan pesan kepada segenap peserta pelatihan untuk menerapkan apa yang telah didapatkan untuk memperbaiki edia audio visual media alat bantu yaitu Media audio visual Peralatan audio visual memungkinkan menggunakan gambar hidup, pemutaran kembali suara, dan penayangan visual yang berukuran besar di sekolah masing-masing. Diharapkan pada Pengabdian Masyarakat yang akan akan datang program ini dapat dilanjutkan lagi dan dapat lebih menjangkau jumlah sekolah lain tak hanya tingkat Sekolah Menengah Pertama (SMPN) saja, sehingga. kebermanfaatan program ini dapat dirasakan oleh sekolah yang lebih banyak.

\section{HASIL DAN PEMBAHASAN}

Guru merupakan salah satu unsur yang menggerakkan pendidikan di Indonesia. Namun, tanpa wawasan yang selalu dikembangkan dan di-up grade maka guru akan makin ketinggalan di era sekarang. Apalagi kebutuhan siswa juga makin berkembang.Lebih lagi, pemanfaatan teknologi di kalangan guru masih dianggap memprihatinkan.Kondisi ini dipengaruhi juga oleh kurangnya fasilitas penunjang pengembangan teknologi pembelajaran disamping sumber daya manusia yang menguasai teknologi masih kurang memadai. Pelatihan ini memberikan beberapa materi yang terkait dengan upaya mengembangkan media audio visual media memungkinkan menggunakan gambar hidup, pemutaran kembali suara, dan penayangan visual yang berukuran besar agar pembelajaran yang diberikan oleh guru menjadi lebih atraktif sehingga meningkatkan minat dan kualitas belajar siswa.

Materi yang disajikan oleh pengabdi dapat diterima, dicerna, dan dipahami peserta dengan baik. Jumlah peserta yang sebanding dengan jumlah pengabdi yang berperan sebagai instruktur dan tutor menjadikan pelatihan ini menjadi lebih kondusif. Hal ini didukung pula dengan kemampuan peserta di bidang computer telah cukup memadai karena pada proses perekrutan telah ditetapkan standar minimal peserta harus telah menguasai computer dasar sehingga pelatihan dapat berjalan lancer dan para peserta dapat berkomunikasi dengan para pembicara dan peserta lain dengan lebih baik. 
Pelatihan ini memberikan beberapa materi yang terkait dengan upaya mengembangkan media pembelajaran interaktif agar pembelajaran yang diberikan oleh guru menjadi lebih atraktif sehingga meningkatkan minat dan kualitas belajar siswa.Materi yang disajikan oleh pengabdi dapat diterima, dicerna, dan dipahami peserta dengan baik. Jumlah peserta yang sebanding dengan jumlah pengabdi yang berperan sebagai instruktur dan tutor menjadikan pelatihan ini menjadi lebih kondusif. Hal ini didukung pula dengan kemampuan peserta di bidang bulutangkis media alat bantu yaitu Media audio visual Peralatan audio visual memungkinkan menggunakan gambar hidup, pemutaran kembali suara, dan penayangan visual yang berukuran besar telah cukup memadai karena pada proses perekrutan telah ditetapkan standar minimal peserta harus telah menguasai computer dasar sehingga pelatihan dapat berjalan lancer dan para peserta dapat berkomunikasi dengan para pembicara dan peserta lain dengan lebih baik.

Berdasarkan diskusi yang dilaksanakan setelah pemapatran materi, dapat dilihat bahwa para guru dapat memahami urgensi pengembangan media pembelajaran, mampu mengenal fungsi program media alat bantu yaitu Media audio visual Peralatan audio visual memungkinkan menggunakan gambar hidup, pemutaran kembali suara, dan penayangan visual yang berukuran besar Berdasarkan hasil karya media yang dibuat para guru, tim juga membuat lembar evaluasi dan menilai karya para guru dan didapat hasil rata-rata B (Baik), dan ada dua orang guru yang mendapat nilai SB (sangat baik). Evaluasi kegiatan dilakukan selama proses kegiatan berlangsung, yaitu pada saat peserta kegiatan melaksanakan proses pembuatan media pembelajaran

Evaluasi hasil dilihat dari tugas praktik para peserta yang ada.Hasil praktiknya dinilai dan hal itu menggambarkan keberhasilan materi yang telah disajikan. Selain itu, secara proses juga dicermati kinerja dan kesertaan para peserta. Di akhir kegiatan Tim menjaring data kebermaknaan program pada para peserta. Teknik evaluasi dilakukan dengan cara observasi, yaitu melihat bagaimana kualitas karya yang dihasilkan. Melakukan wawancara yaitu memberi berbagai pertanyaan yang terkait dengan pelaksanaan kegiatan baik secara individu maupun secara kelompok.Selain itu, memberi angket untuk mengetahui bagaimana tanggapan peserta tentang pelaksanaan kegiatan pelatihan pembuatan media pembelajaran interaktif dengan pemanfaatan program yang telah dilaksanakan.Untuk menjaring respon peserta terhadap kebermanfaatan dan kebermaknaan program ini dilakukan evaluasi respon terhadap kegiatan pelatihan. Berikut adalah tabel instrumen evaluasi respon peserta terhadap kegiatan pelatihan pembuatan media pembelajaran interaktif dengan pemanfaatan media alat bantu yaitu Media audio visual Peralatan audio visual memungkinkan menggunakan gambar hidup, pemutaran kembali suara, dan penayangan visual yang berukuran besar.

Tabel Insstrument evaluasi respon peserta terhadap KEGIATAN pelatihan penelitian dilaksanakan di SMP

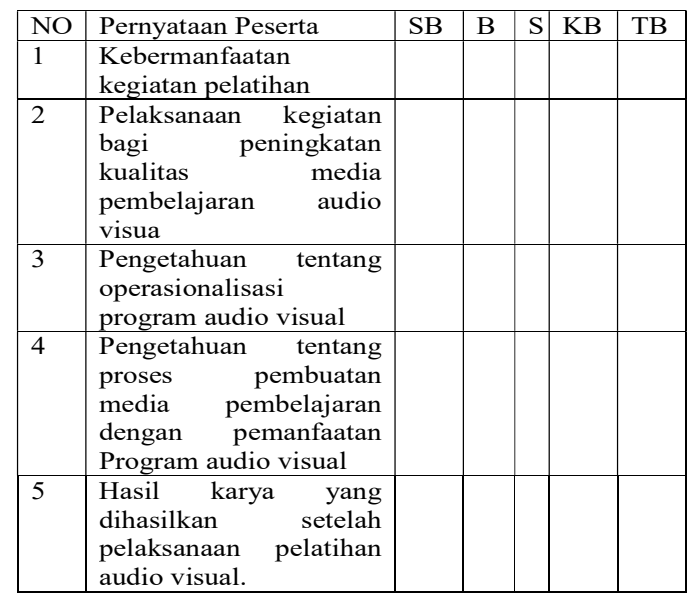

Keterangan: SB : Sangat Baik B : Baik S : Sedang KB : Kurang Baik TB : Tidak Baik

Dari angket tersebut dapat disimpulkan bahwa para peserta dapat memperoleh manfaat dari program pelatihan ini untuk meningkatkan kualitas media pembelajaran, mengetahui cara pengoperasionalisasian program media alat bantu yaitu Media audio visual Peralatan audio visual memungkinkan menggunakan gambar hidup, pemutaran kembali suara, dan penayangan visual yang berukuran besar, dan mampu membuat media pembelajaran sesuai dengan mata pelajaran yang diampu masing- 
masing peserta. Kegiatan Pengabdian pada Masyarakat ini telah terlaksana dengan baik berkat dukungan berbagai faktor yaitu:Komunikasi antar anggota tim berlangsung lancar dan efektif sehingga koordinasi tim pada proses persiapan, pembagian tugas, pelatihan dan simulasi dapat berlangsung dengan baik dan tepat waktu, peserta pelatihan yang terdiri dari guru SMPN 1 Mataram pada semester genap tahun pelajaran genap 2018/2019.

\section{KESIMPULAN}

Materi yang disajikan dapat diterima, dicerna, dan dipahami peserta dengan baik. melalui pembelajaran media alat bantu yaitu Media audio visual Peralatan audio visual memungkinkan menggunakan gambar hidup, pemutaran kembali suara, dan penayangan visual yang berukuran besar hidup, menggunakan media alat bantu telah berhasil dalam proses kegiatan peningkatan keterampilan servis backhand bulutangkis

\section{SARAN}

pendidik (guru) pendidikan jasmani SMPN 1 Mataram, diharapkan dapat menggunakan metode media alat bantu yang merupakan salah satu metode untuk memodernkan proses pembelajaran formal maupun informal terutama pada materi keterampilan servis backhand bulutangkis.

\section{DAFTAR PUSTAKA}

Sukmadinata, Nana Syaodih. Metode Penelitian Tindakan. Bandung: PT Remaja Rosdakarya. 2011.

Mertler, Craig A..Action Research. Yogyakarta: Pustaka Pelajar. 2011.

Widiastuti.Tes dan Pengukuran Olahraga. Jakarta: PT. Raja Grafindo Persada. 2015.

Honeybourne, John. Acquiring Skill in Sport.The Taylor \& Francis Group. 2004

Schimtd, Richard A. dan Timothy D. Lee, Motor Control and Learning: A

Behavioral Emphasis Fifth Edition USA: Human Kinetics. 2011.

James Poole. Belajar Bulutangkis. Bandung: Pionir Jaya. 2013.
Aksan, Hermawan. Mahir Bulutangis. Bandung: Nuansa Cendekia. 2012.

Marwan, Iis. Pengantar Metode Penelitian Pendidikan Olahraga.

Tasikmalaya: Universitas Siliwangi. 2014. Arsyad, Azhar. Media Pembelajaran. Jakarta: PT. Grafindo Persada. 